\title{
An interface board for developing control loops in power electronics based on microcontrollers and DSPs Cores -Arduino /ChipKit/dsPIC /DSP /TI Piccolo
}

Pittini, Riccardo; Zhang, Zhe; Andersen, Michael A. E.

Published in:

The 14th IEEE Workshop on Control and Modeling for Power Electronics

Publication date:

2013

Link back to DTU Orbit

Citation (APA):

Pittini, R., Zhang, Z., \& Andersen, M. A. E. (2013). An interface board for developing control loops in power electronics based on microcontrollers and DSPs Cores -Arduino /ChipKit /dsPIC /DSP /TI Piccolo. In The 14th IEEE Workshop on Control and Modeling for Power Electronics IEEE.

\section{General rights}

Copyright and moral rights for the publications made accessible in the public portal are retained by the authors and/or other copyright owners and it is a condition of accessing publications that users recognise and abide by the legal requirements associated with these rights.

- Users may download and print one copy of any publication from the public portal for the purpose of private study or research.

- You may not further distribute the material or use it for any profit-making activity or commercial gain

- You may freely distribute the URL identifying the publication in the public portal 


\section{An Interface Board for Developing Control Loops in Power Electronics Based on Microcontrollers and DSPs Cores -Arduino /ChipKit /dsPIC /DSP /TI Piccolo}

\author{
Riccardo Pittini \\ Dept. of Electrical Engineering \\ Technical University of Denmark \\ 2800 Kgs. Lyngby, Denmark \\ ripit@elektro.dtu.dk
}

\author{
Zhe Zhang \\ Dept. of Electrical Engineering \\ Technical University of Denmark \\ 2800 Kgs. Lyngby, Denmark \\ zz@elektro.dtu.dk
}

\author{
Michael A.E. Andersen \\ Dept. of Electrical Engineering \\ Technical University of Denmark \\ 2800 Kgs. Lyngby, Denmark \\ ma@elektro.dtu.dk
}

\begin{abstract}
In this paper a new control-interface card for developing simple control loops and generating test signals for power electronic converters is presented. The control board can operate with two computational cores (Texas Instruments and Microchip) allowing using the preferred DSP architecture and development environment. Moreover, the interface board can operate with open hardware Arduino-like boards such as the ChipKit Uno32. The paper also describes how to enhance the performance of a ChipKit Uno32 with a dsPIC obtaining a more suitable solution for power electronics. The basic blocks and interfaces of the boards are presented in detail as well as the board main specifications. The board operation has been tested with three core platforms: TI Piccolo controlSTICK, a Microchip dsPIC and a ChipKit Uno32 (Arduino-like platform). The board was used for generating test signals for characterizing $1200 \mathrm{~V} \mathrm{Si}$ and $\mathrm{SiC}$ power semiconductors. A $6 \mathrm{~kW}$ dc-dc converter prototype is presented; the converter is based on the developed interface board.
\end{abstract}

\section{INTRODUCTION}

As green energy is getting more important, developing optimized power electronic converters is becoming more and more complex. Developments in new power semiconductors such as silicon carbide ( $\mathrm{SiC}$ ) together with new topologies and control strategies resulted in commercially available $99 \%+$ efficiency power converters (examples of $99 \%+$ efficiency SMA solar inverter [1], and converter prototypes [2][3]). High efficiency designs are challenging, require advance knowledge in power electronics and also in digital electronics. In fact, novel and complex modulations strategies are mostly implemented on microcontrollers (uCs) or more commonly digital signal processors (DSPs [4]) and field programmable gate arrays (FPGAs [5]). Boards hosting DSPs require variety of auxiliary circuitry for signal conditioning and powering all auxiliary peripherals which are required for a proper operation of the power electronics converter. On the market there is a large availability of control boards for power electronics: some solutions allow focusing on development-optimization of control loops and modulations strategies without having detailed knowledge about DSP architectures [6]. These solutions are very flexible and suited for developing prototypes or proof of concepts however, they often tend to be costly and not always suited for the single research groups. Other available solutions are represented by development kits provided by several microcontrollers, DSPs and FPGAs manufacturers. These boards necessitate of various external components and the developer is often designing his own interface boards, since commercial boards are often overwhelmed with functions. The lack of availability is mainly due to the fact that each application is different and requires a custom-designed controller board depending on the design needs.

In recent years Arduino-like platforms have seen enormous diffusion both in amateur applications and in research environments due to their simplified programming language and low-cost [7]-[9]. The spreading of the new open hardware platform led to an increase of available "interface shields"; this increased furthermore the flexibility of the Arduino platforms which started to spread in most of the academic environments. In the development of control loops for power electronic converters, the platform was not really successful probably due to the limited performances of the microcontrollers which the boards are based on or the lack of availability of suitable interface boards for power electronics.

The paper presents an interface board that can be used for developing power electronics test platforms and control loops. The interface board can operate with the low-cost TI Piccolo controlSTICKs or with an Arduino-based platform like the Arduino 2009 or the ChipKit Uno32. For increasing the performance of the Arduino-like platforms the paper proposes the replacement of the original microcontroller on ChipKit Uno32 boards with a more performance dsPIC which performance are similar to the TI platform. The interface board can be operated with the desired core and simply

Project sponsored by the Energy Technology Development and Demonstration Programme (EUDP) "Green Natural Gas", 2011-2014. 
(a)

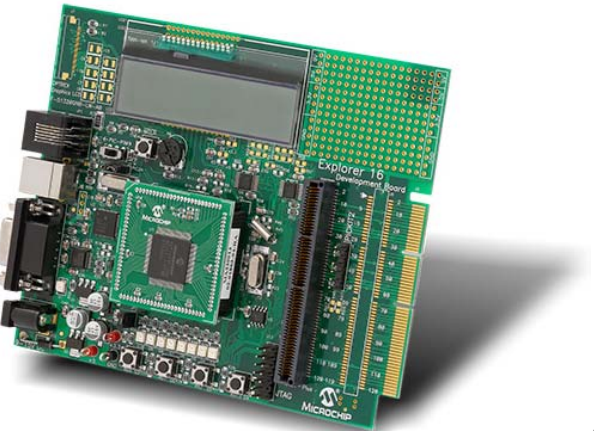

(b)

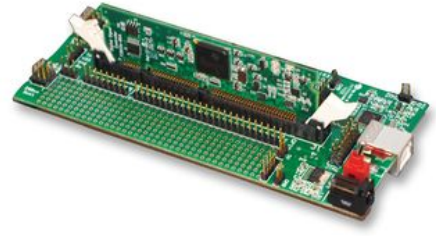

(c)

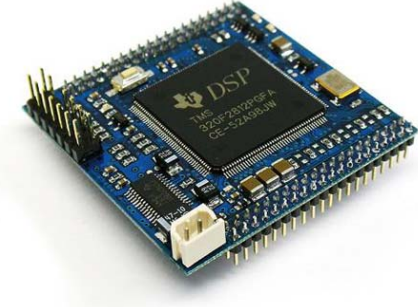

Fig. 1. Commercially available development boards for power electronics and signal conditioning applications. Microchip dsPIC development board (a), TI controlCARD F28035 (b) and DSP header board F2812 (c).

programmed with the available tools from the manufactures (e.g. Texas Instruments Code Composer Studio or Microchip MPLAB). The developed interface board was used for generating test signals and characterizing the switching performance of $1200 \mathrm{~V} \mathrm{Si}$ and $\mathrm{SiC}$ power semiconductors [10][11]. Moreover, a $6 \mathrm{~kW}$ dc-dc isolated boost full bridge converter prototype was developed and tested with the presented interface board [11].

\section{CONVENTIONAL POWER ELECTRONICS CONTROL BOARDS AND INTERFACES}

Conventional platforms utilized for developing control loops for power electronic converter prototypes have a main core (e.g. uC, DSP, FPGA) surrounded by additional signal conditioning circuitry, general $\mathrm{I} / \mathrm{O}$ interfaces and ports (Fig. 1a). These boards tend to have a large number of features and during the development of a converter prototype most of these features remains unused. Moreover, these boards tend to be costly also due to the large number of embedded features. Some development boards have minimal embedded circuitry which is just sufficient for generic data transfer and for board programming (Fig. 1b). This approach often utilizes a daughter board which can be used to develop customized signal conditioning circuitry depending on the project needs. Another approach utilizes "core boards" (Fig. 1c); in this case

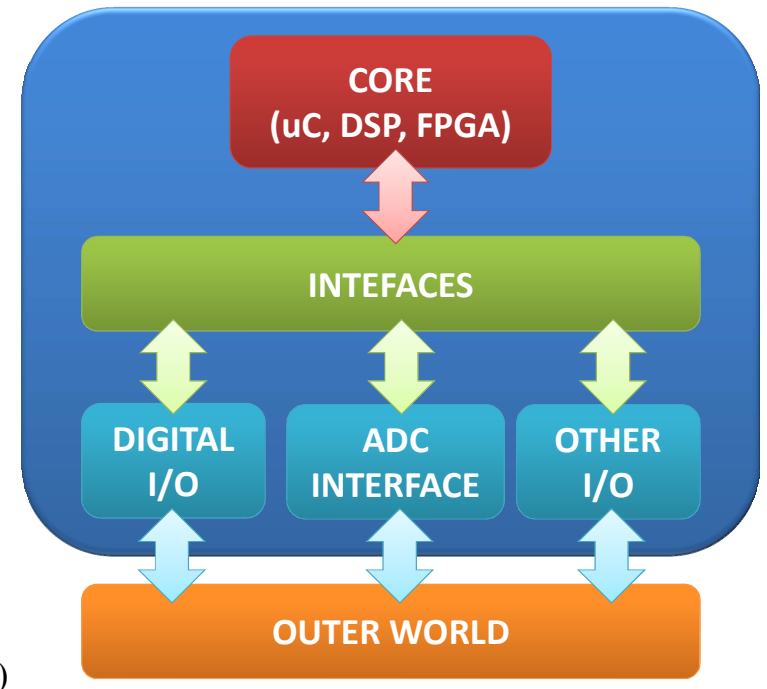

the board hosts uniquely the main core (e.g. uC, DSP, FPGA), the core power stage and the programming interface. All other I/Os are directly interfaced to the main core with no signal conditioning circuitry along the path. In some products, different cores are implemented on a single board (e.g. DSP with FPGA) providing additional functionality and enhanced possibilities for customization of the core functionalities. All these platforms have a common structure that can be summarized as Fig. 2a. This structure is based on a fixed core which cannot be exchanged with other cores. These solutions often limit the developer to the development tools from the board supplier or manufacturer moreover, migrating towards another DSP architecture is complex and time demanding.

\section{A NeW CONCEPT FOR A FlEXIBLE POWER ELECTRONICS CONTROL BOARDS}

A new controller card for quick prototyping and developing control loops for power electronic converters was developed. The main concept behind the developed board is its multi-platform support, Fig. 2b. The interface board is compatible with the two most used DSP development tools in power electronics: Code Composer Studio from Texas Instruments and MPLAB from Microchip. Moreover, in order to allow fast prototyping, the board has an interface compatible with an Arduino board (e.g. Arduino 2009 or

(b)

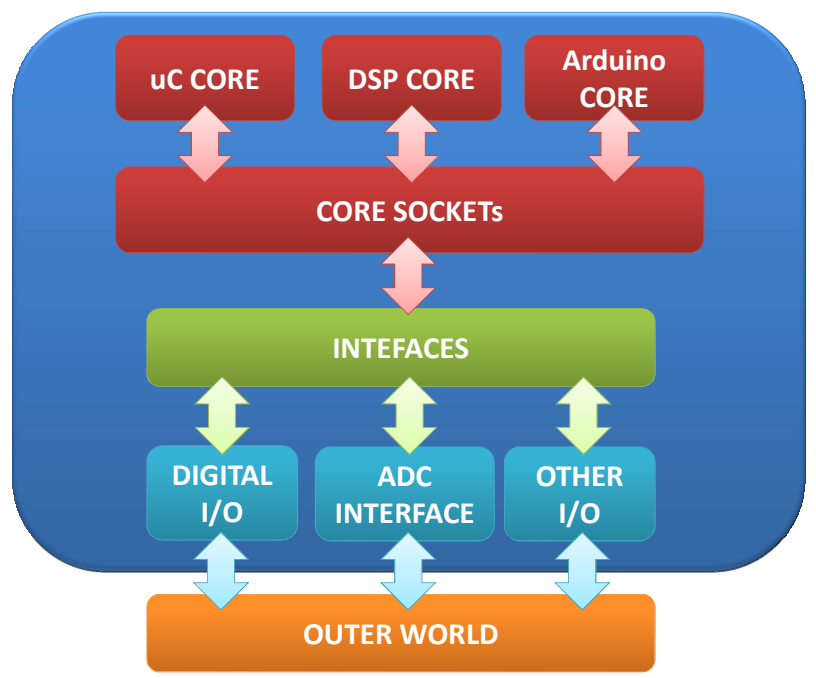

Fig.2. Conventional block structure for power electronics control boards (a) and structure of the designed interface board based on multi-platform support (b). 


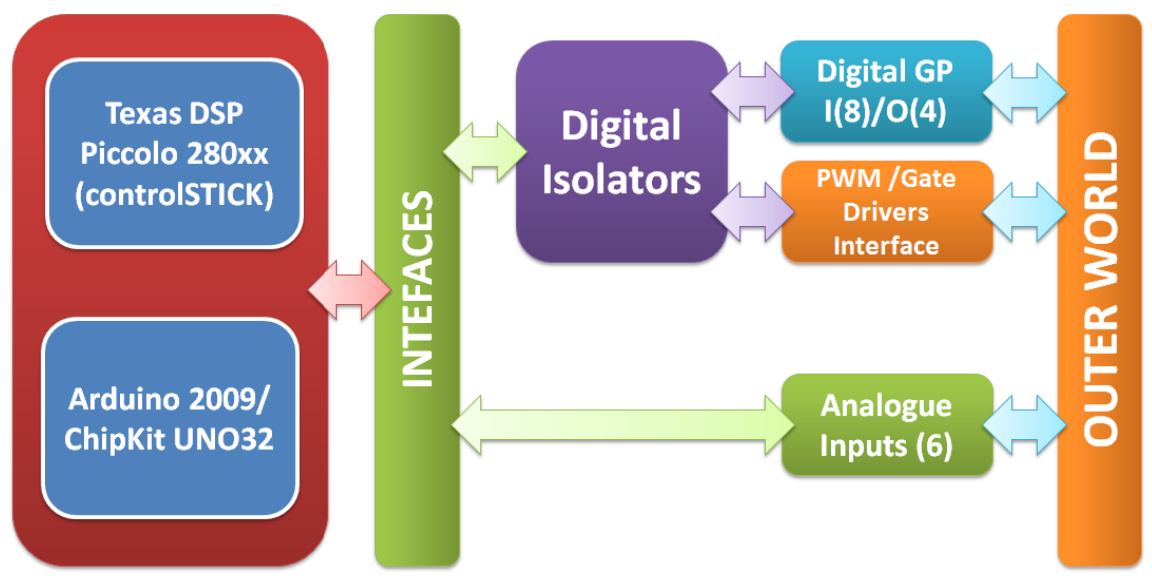

Fig. 3. Block overview of the designed interface board for TI Piccolo controlSTICK /Arduino 2009 /ChipKit Uno32 /dsPIC.

ChipKit Uno32). The board has different interface sockets, these allow the board to interface to different commercial DSP boards such as the TI Piccolo controlSTICK of the ChipKit Uno32 (Arduino-like platform). Only one of the selected platforms can be used on the interface board; operating with multiple cores at the same time it is not possible due to interface sharing. The designed interface board offers the possibility of developing test signals or control loops based on the preferred core architecture. Moreover, the support of Arduino-like boards and, therefore, of the Arduino environment (simplified $\mathrm{C}$ programming) allows fast prototyping.

The development has been focused on maintaining wide application-flexibility, contained costs and simplicity. The desired interface board can operate with two different DSP cores (block structure on Fig. 3); it is suitable for developing test signals and control loops for hard switching power electronic converters in the $1-10 \mathrm{~kW}$ range which usually has switching frequencies below 200-300 kHz [12][13] for hard switched converters. The board is developed for being used with ac/dc or $\mathrm{dc} / \mathrm{dc}$ converter and, in general, with isolated or non-isolated converters. The board main requirements are: 4 PWM channels (complementary), 4 analog input channels (min $10 \mathrm{bit}$ ), A/D $>500 \mathrm{kS} / \mathrm{s}$, digital isolation and some additional GPIO.

Most of the commercially available DSPs match these specifications; however, the development has been focused on two main platforms: TI Piccolo controlSTICK [14] and Arduino /ChipKit Uno32 [15]. The TI Piccolo controlSTICK is often used in power electronics due to its relatively low cost, flexibility and features. The open hardware Arduino /ChipKit Uno32 can represent a suitable starting point for amateur use. However, in power electronics, the Arduino platform has several computational and timing limitations due to the limited performance of the onboard microcontrollers. The Uno32 is based on a 32 bit microcontroller which is pin to pin compatible with other DPSs from Microchip (dsPIC [16]). This makes the Uno32 board a good backbone for a dsPICbased board (e.g. 33FJ64GS606) which is more suited for power electronics.

All platforms require external circuitry to be able to develop a complete control system for a power electronic converter (external power supplies for gate drivers, filtering of $\mathrm{A} / \mathrm{D}$ channels, isolation of digital signals, voltage references, etc). In power converters the control circuitry can be located far from the converter power stage; however, some components such as gate drivers and sensors (current and voltage) have to be located close to the power circuitry. For this reason, the interface board does not integrate gate drivers and sensors. Since Arduino-like platforms are widely spread, the developed interface board will be compatible with Arduino 2009 systems. However, the main target cores will remain a Uno32 based on a dsPIC33 and a TI Piccolo controlSTICK.

(b)

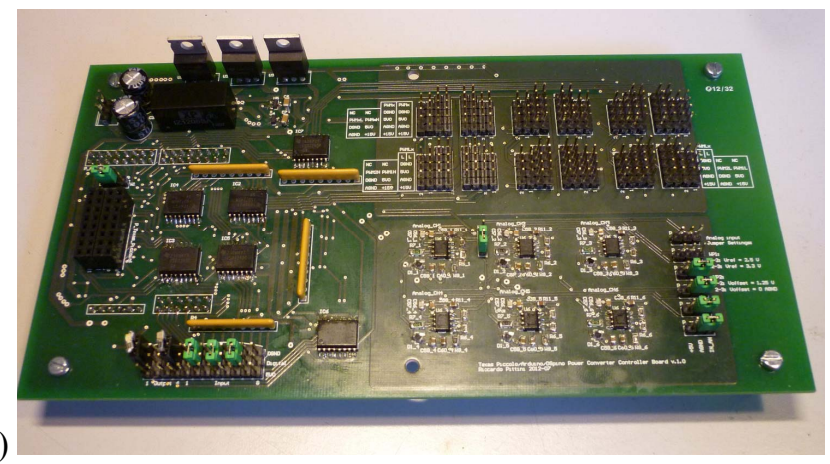

(a)

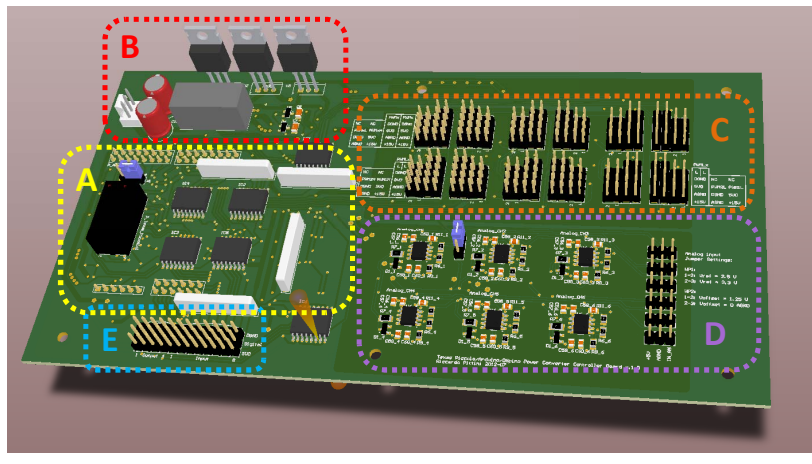

Fig.4. 3D model of the designed interface board highlighting its main interface blocks (a) and developed prototype (b). 

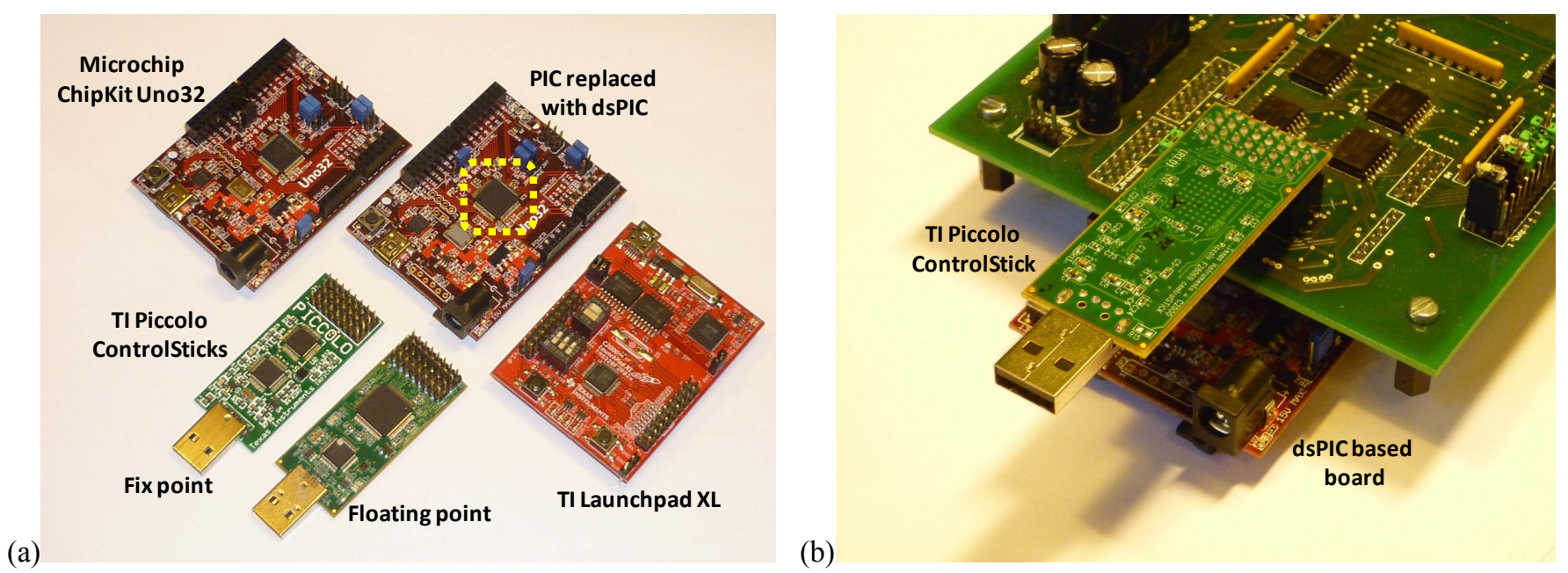

Fig. 5. Core boards (a) and core boards installed on the interface board (b). NB: the core boards cannot be used simultaneously.

\section{DESCRIPTION OF MAIN BLOCKS AND INTERFACES}

The developed board is an interface board whose main functional blocks (Fig. 4a) are described below and an overview of the board prototype is presented on Fig. $4 \mathrm{~b}$.

\section{A. Arduino/dsPIC /DSP TI Piccolo controlSTICK Connectors}

The board features the capability of operating with a TI Piccolo controlSTICK or with an Arduino /ChipKit Uno32 /dsPIC which represent the computational cores of the board. All digital I/O of the platforms are isolated through high speed capacitive isolators providing also voltage level shifting (up to $5 \mathrm{~V}$ ) and higher I/O current capability (up to $15 \mathrm{~mA}$ per I/O). I/O capability is limited by the selected platform. On one ChipKit Uno32 the original microcontroller was replaced with a more powerful dsPIC more suitable for controlling power electronic converters (Fig. 5a). The interfacing sockets are located on top and on the bottom of the board, Fig. 5b.

\section{B. Integrated Power Supply and Voltage References}

The board is supplied with dual $12-15 \mathrm{~V}$. The $+12 / 15 \mathrm{~V}$ rail directly powers the gate driver connectors and has to ensure sufficient power for driving the power semiconductors (gate drivers). Additional dual $5 \mathrm{~V}$ are used for powering the onboard op-amps. The board features a $3 \mathrm{~W}$ isolated $\mathrm{dc} / \mathrm{dc}$ power supply for generating the digital rail voltages required for the DSP and the digital ICs (5 V and 3.3 V).

The board grounds (analog and digital) were kept separately; however, since low-cost DSP boards like the TI Piccolo controlSTICK does not have separate analog and digital grounds, there is always one point of common coupling for the two grounds (DSP board). Ferrite beads can be placed between the two board grounds (maintaining the common coupling point); alternative, 0 -Ohm resistors can be replace the ferrite beads depending on the system ground configuration. This section of the board also integrates two auxiliary voltage reference required as auxiliary reference for the $\mathrm{A} / \mathrm{D}$ converter $(+2.5 \mathrm{~V})$ and $+1.25 \mathrm{~V}$ used as DC-bias.

\section{Gate Driver/PWM Interface}

The gate driver interface (PWM connectors on Table I) provides up to six complementary PWM channels. The connectors also provide analog supply $(+12 / 15 \mathrm{~V}$ depending on the board supply voltage) and digital supply ( $+5 \mathrm{~V})$ useful for powering directly the gate drivers and local signal conditioning logic. The gate driver connectors are grouped into three main categories depending on the PWM signals they provide. The complementary connectors provide two PWM signals (complementary connector CPWMx) suited for a phase-leg of a voltage source converter. The boost full bridge PWM connectors provide two independent PWM signals (e.g. PWM1 and PWM2, connector BPWMx) ideal for driving the phase legs in a full bridge isolated boost converter and the single gate driver connectors are a general purpose singlePWM channel.

TABLE I. GATE DRIVER - PWM CONNECTORS

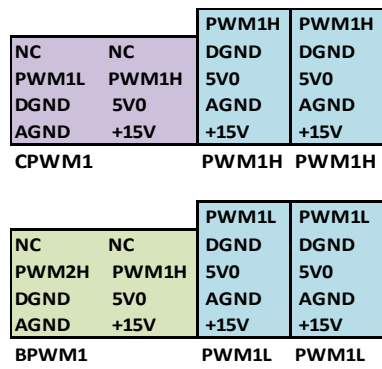

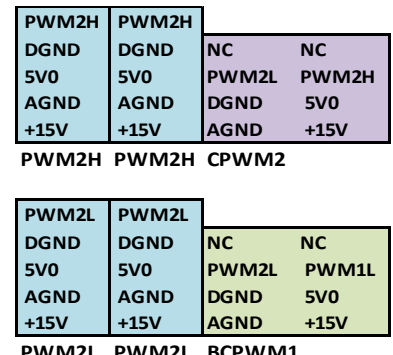




\section{Analog Input Interface}

The board has the capability of receiving six unipolar analog signals. When the board is powered by a TI Piccolo, the internal $\mathrm{ADC}$ operates at 12 bit resolution while, with a dsPIC, the resolution is limited to 10 bit. The analog connectors provide also a $5 \mathrm{~V}$ supply for powering the sensor (e.g. LEM module). Each analog channel has signal conditioning circuitry: operational amplifiers add dc-bias, moreover they perform a second order active filtering (SallenKey filter) and scaling. The op-amps have a dual power supply to ensure linear operation in the $0-3.3 \mathrm{~V}$ range (minmax ADC range).

\section{E. General Purpose I/O}

The interface board also provides 12 isolated $5 \mathrm{~V}$ general purpose inputs (8) and outputs (4) (GPIO). Since the selected digital isolators are unidirectional devices, the input /output pins cannot be reconfigured.

\section{Development ToOls AND New DSPIC-BASED CHIPKIT}

The standard Arduino development environment cannot provide suitable performances for developing complex control systems. Moreover, the performances of on board microcontroller on Arduino-like platforms are too low for the specified requirements. This reduces the choice to two main solutions: the TI Piccolo controlSTICK and a ChipKit Uno32 based on a dsPIC. For these platforms the manufacturers provide suitable development tools with some limitations for the free versions (TI Code Composer Studio [14] and Microchip MPLAB [16]).

The use of Arduino environment is limited to the supported microcontrollers. This represents the main limitation in terms of performance and resources. Moreover, the Arduino development environment (or Arduino-like environments) does not provide support for dsPICs. A commercial Arduino platform can still be used with the designed interface board; this will have some limitations in terms of performances (e.g. low A/D sampling rate), available resources and DSP features.

(a)

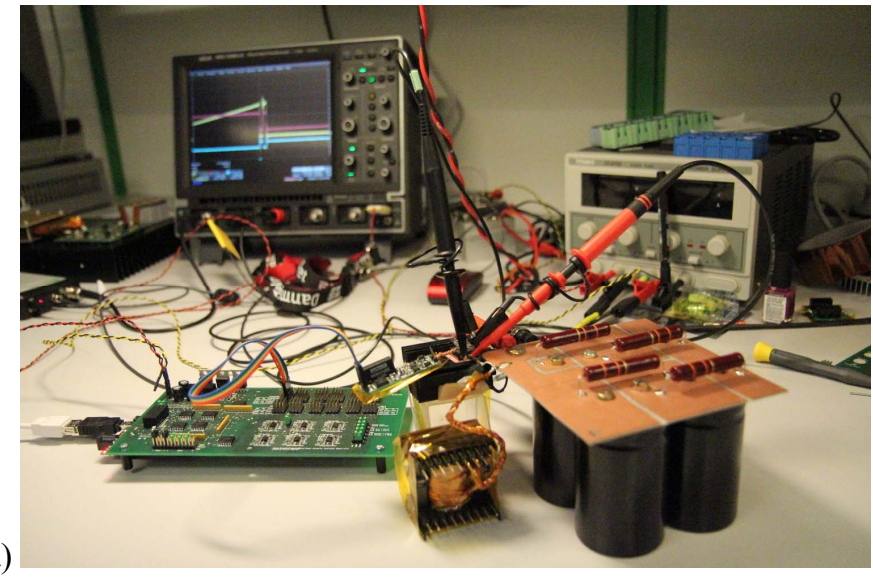

On one ChipKit Uno32, the original onboard microcontroller (PIC32MX320F128H) was replaced with a dsPIC (33FJ64GS606, Fig. 5a) which is a digital signal controller with features for power electronics. The replacement of the original microcontroller was possible since the pin layout of the PIC32 and dsPIC families (e.g. 33F series 64-pin TQFP package) are compatible for the same package type. This solution is more suitable for designing control loops for power electronic converters, since it is possible to benefit of all DSP functionalities of the dsPIC family. The main drawback of this solution is that it is not possible to program the platform with the Arduino environment as previously done for the PIC32 (simplified C programming language). With the new dsPIC it is required to use development tools that support these devices such as MPLAB. The solution gives a significant performance and features increase thanks to the DSP functionalities of the dsPIC (e.g. faster PID execution due to the dedicated DSP functionalities).

\section{EXPERIMENTAL TESTS AND PROTOTYPE OF A DC-DC CONVERTER}

The functionality of the interface board was tested with a TI Piccolo controlSTICK, a ChipKit Uno32 and a ChipKit Uno32 modified with a dsPIC. When using the ChipKit Uno32 the board was programmed in Arduino-like environment for generating double pulse test signals for measuring the switching performance of $1200 \mathrm{~V} \mathrm{Si}$ and $\mathrm{SiC}$ power semiconductors, Fig. 6a. The Arduino-like environment allowed to easily creating a USB-serial interface that could vary the pulse width and, therefore, the test conditions for the power semiconductor through a computer interface. This setup on Fig. 6a is often referred as double pulse test circuit; it was used to characterize the switching performance of power semiconductors such as $\mathrm{Si}$ IGBTs, SiC JFETs and $\mathrm{SiC}$ MOSFETs in [10][11]. During these test it was important to maintain exactly the same pulse width (therefore, the same testing current, Fig. 6b, to guarantee that the test conditions were maintained the same for different power semiconductors. In this case, the main advantage was that the pulse and test repeatability was higher than when an analog pulse generator is used.

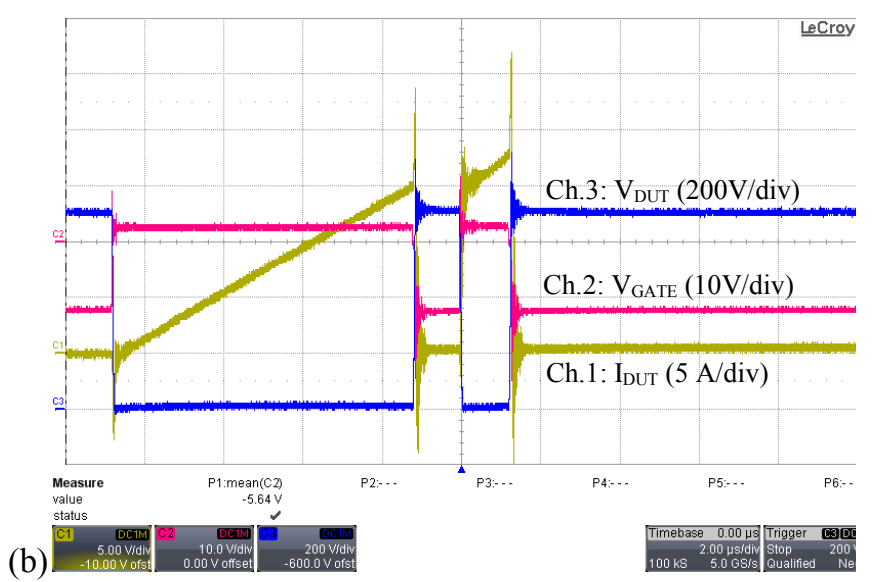

Fig. 6. Interface board used in a test bench for characterizing $1200 \mathrm{~V} \mathrm{Si}$ and $\mathrm{SiC}$ power semiconductors switching performance (a) and measured waveforms across the power semiconductors. Pulses were generated with the control card and a gate driver for properly driving the power semiconductors (b). 

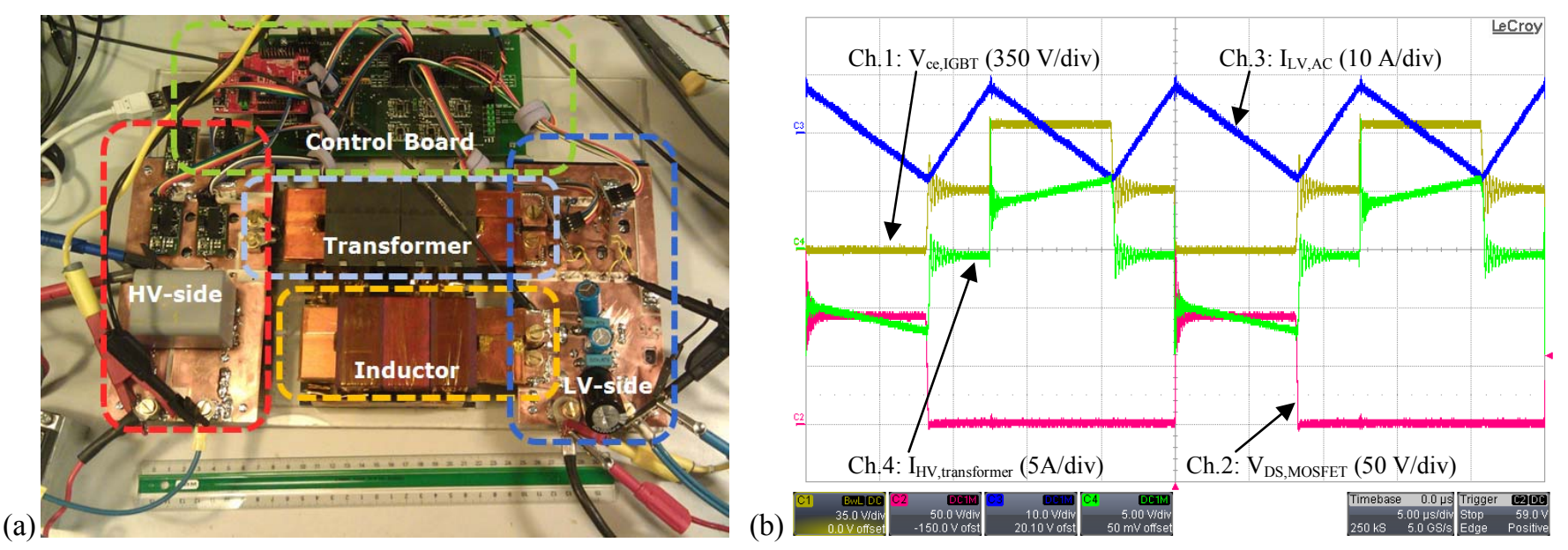

Fig.7. Developed prototype of the dc-dc converter with the interface board (a) and switching waveforms (b) at $60 \mathrm{~V} 40 \mathrm{~A}$ on the low voltage side and $750 \mathrm{~V}$ on the high voltage side in SOFC mode. Ch.1(yellow): $\mathrm{V}_{\text {ce,IGBT }}(350 \mathrm{~A} / \mathrm{div}), \mathrm{Ch} .2$ (red): $\mathrm{V}_{\mathrm{ds}, \mathrm{MOSFET}}(50 \mathrm{~V} / \mathrm{div}), \mathrm{Ch} .3$ (blue): $\mathrm{I}_{\mathrm{LV}, \mathrm{AC}}(10 \mathrm{~A} / \mathrm{div})$,

Ch.4(green): $\mathrm{I}_{\mathrm{HV} \text {,transformer }}(5 \mathrm{~A} / \mathrm{div})$. Time $5 \mu \mathrm{s} / \mathrm{div}$.

A $6 \mathrm{~kW}$ bidirectional dc-dc isolated full bridge boost converter (IFBBC) prototype was developed [11], Fig. 7a. The converter low voltage side is characterized by and $30-80 \mathrm{~V}$ range with current up to $80 \mathrm{~A}$ (current limitation). The converter high voltage side is designed as dc-link for a $400 \mathrm{~V}_{\text {rms }}$ grid-tie inverter with a dc-link voltage in the 700$800 \mathrm{~V}$ range. The converter uses Si MOSFETs on the low voltage side and $\mathrm{Si}$ IGBTs with $\mathrm{SiC}$ antiparallel diodes on the high voltage side. The converter is switching at $40 \mathrm{kHz}$ and its main waveforms are presented on Fig. 7b. The converter control boards is based on the developed interface board and the main core is a ChipKit Uno32 modified with a dsPIC. The converter was tested at different voltage levels, power levels and characterized in efficiency terms. Efficiency characterization is shown on Fig 8a with the power flow from the low voltage to the high voltage side and on Fig. $8 \mathrm{~b}$ with the power flowing form the high voltage side to the low voltage one. Respectively the peak efficiencies are $97.8 \%$ and
$96.5 \%$ both at $80 \mathrm{~V}$ (maximum voltage on the converter low voltage side). At lower voltages $(30 \mathrm{~V})$ the peak efficiency is limited to $\sim 96 \%$ and to $93 \%$ depending on the power flow direction.

\section{CONCLUSIONS}

When developing control loops and test setups for power electronics converters choosing the suitable development tool is often a challenge that takes into account personal skills, available time and cost. The paper has presented a simple and flexible solution for developing controls of power electronics converters which can operate with different microcontrollers or DSP platforms (open hardware Arduino /ChipKit Uno32 /TI Piccolo controlSTICK). The board has the potential to reduce the prototyping time since it allows using the preferred DSP /microcontroller technology and development tools (e.g. Arduino, Texas Code Composer Studio or Microchip MPLAB). The support of the Arduino environment can
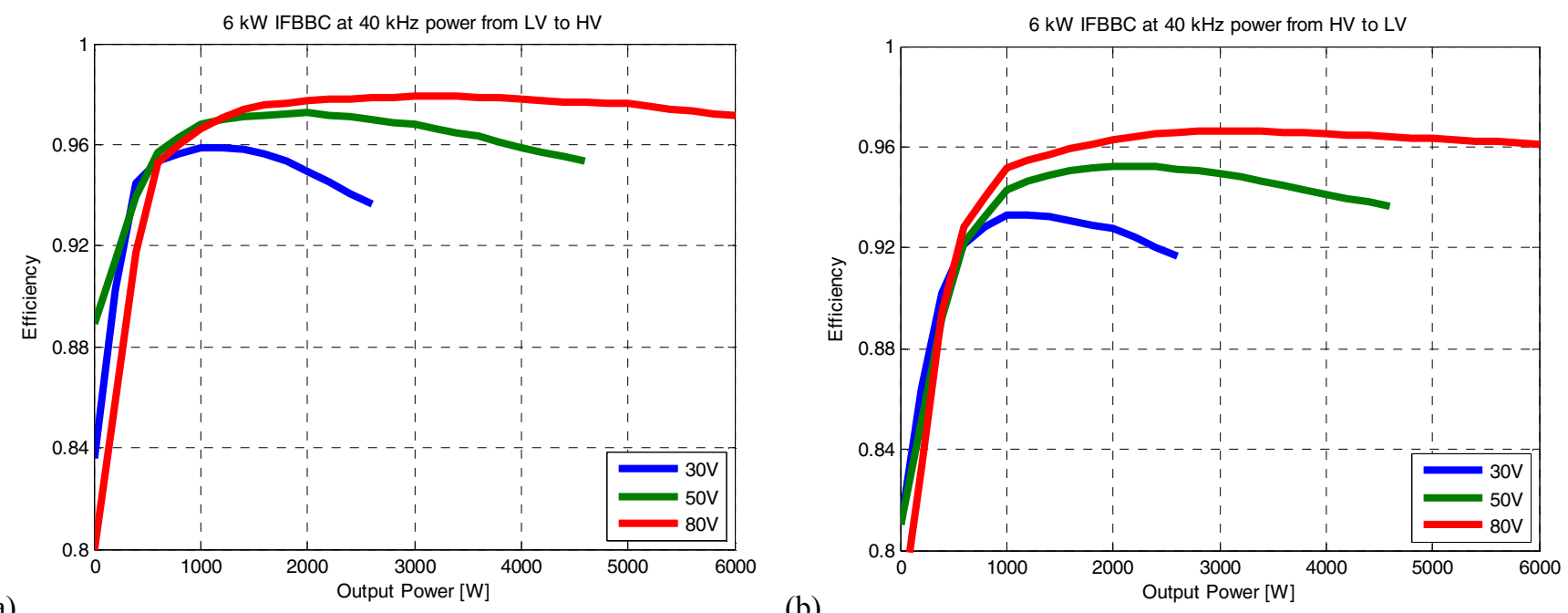

(a)

Fig. 8. Dc-dc converter efficiency characterization at different voltage and power levels. Power flow from the low voltage to the high voltage side (a) and from the high voltage to the low voltage side (b). 
significantly reduce the development time due to the simplified programming language. Moreover, to overcome the limitations of the conventional platforms based on Arduinosupported microcontrollers, the paper recommends replacing the PIC32 on a ChipKit Uno32 with a dsPIC of the "33FxxxGSxxx" family. In this way the interface board would benefit from enhanced DSP functionalities especially suited for closed loop control of power electronics converters.

The developed interface board was successfully used for generating test signals to characterize the switching performance of $1200 \mathrm{~V} \mathrm{Si}$ and $\mathrm{SiC}$ power semiconductors. Moreover, the board was used in the development of a high efficiency dc-dc isolated full bridge boost converter prototype achieving peak efficiencies of $97.8 \%$ and $96.5 \%$ depending on the converter power flow.

\section{REFERENCES}

[1] Regine Mallwitz, "First 99\% PV Inverter with SiC JFETs on the market - future role of SiC", Power Conversion Intelligent Motion Conference, PCIM Europe 2012, 8-10 May 2012, Nurenberg, Germany.

[2] Rabkowski, J.; Peftitsis, D.; Nee, H.-P.; , "Design steps towards a 40kVA SiC inverter with an efficiency exceeding 99.5\%", TwentySeventh Annual IEEE Applied Power Electronics Conference and Exposition (APEC 2012), pp.1536-1543, 5-9 Feb. 2012.

[3] Badstuebner, U.; Biela, J.; Kolar, J.W.; , "Design of an 99\%-efficient, $5 \mathrm{~kW}$, phase-shift PWM DC-DC converter for telecom applications",Twenty-Fifth Annual IEEE Applied Power Electronics Conference and Exposition (APEC 2010), pp.773-780, 21-25 Feb. 2010.

[4] Kirubakaran, K.; Jain, S.; Nema, R.K.; , "DSP-Controlled Power Electronic Interface for Fuel-Cell-Based Distributed Generation", IEEE Transactions on Power Electronics, vol.26, no.12, pp.3853-3864, Dec. 2011.

[5] Sugahara, K.; Oida, S.; Yokoyama, T.; , "High performance FPGA controller for digital control of power electronics applications", IEEE $6^{\text {th }}$ InternationalPower Electronics and Motion Control Conference, 2009 (IPEMC '09), pp.1425-1429, 17-20 May 2009.

[6] Li Weichao; Hu An; Geng Shiguang; Sun Chi, "Rapid control prototyping of fifteen-phase induction motor drives based on dSPACE," International Conference on Electrical Machines and Systems (ICEMS 2008), pp.1604-1607, 17-20 Oct. 2008.

[7] Sarik, J.; Kymissis, I.; , "Lab kits using the Arduino prototyping platform," IEEE Frontiers in Education Conference (FIE), 2010, pp.T3C-1-T3C-5, 27-30 Oct. 2010.

[8] Buechley, L.; Eisenberg, M.; , "The LilyPad Arduino: Toward Wearable Engineering for Everyone," IEEE Pervasive Computing, vol.7, no.2, pp.12-15, April-June 2008.

[9] Kioumars, A.H.; Liqiong Tang; , "Wireless network for health monitoring: heart rate and temperature sensor", Fifth International Conference on Sensing Technology (ICST 2011), pp.362-369, Nov. 28 2011-Dec. 1, 2011.

[10] Pittini, Riccardo; Zhang, Z.; Andersen, A.E.M., "SiC JFET Cascode Loss Dependency on the MOSFET Output Capacitance and Performance Comparison with Trench IGBTs", Twenty-Eight Annual IEEE Applied Power Electronics Conference and Exposition (APEC 2013), pp.1287-1293, 17-21 March 2013.

[11] Pittini, Riccardo; Zhang, Z.; Andersen, A.E.M., "Switching Performance Evaluation of Commercial SiC Power Devices (SiC JFET and $\mathrm{SiC}$ MOSFET) in Relation to the Gate Driver Complexity", $5^{\text {th }}$ Annual International Energy Conversion Congress and Exhibition in Asia (ECCE Asia 2013), 3-6 June 2013.

[12] Sanbo Pan; Mi, C.; Lin, T.; , "Design and testing of silicon carbide JFETs based inverter," IEEE $6^{\text {th }}$ International Power Electronics and Motion Control Conference, 2009. IPEMC 2009, pp.2556-2560, 17-20 May 2009.
[13] Simanjorang, R.; Yamaguchi, H.; Ohashi, H.; Nakao, K.; Ninomiya, T.; Abe, S.; Kaga, M.; Fukui, A.; , "High-efficiency high-power dc-dc converter for energy and space saving of power-supply system in a data center," Twenty-Sixth Annual IEEE Applied Power Electronics Conference and Exposition (APEC 2011), pp.600-605, 6-11 March 2011.

[14] Texas Instruments Piccolo controlSTICK, www.ti.com.

[15] Digilent ChipKit Uno32, www.digilentinc.com.

[16] Microchip dsPIC series, www.microchip.com. 